\title{
Influence of Growth Conditions and Doping on Physical Properties of Gallium Antimonide Single Crystals
}

\author{
A. Mirowska and W. OreOWSKI \\ Institute of Electronic Materials Technology, Wólczyńska 133, 01-919 Warsaw, Poland
}

\begin{abstract}
Gallium antimonide (GaSb) single crystals were grown by modified Czochralski method integrated with in situ synthesis in a flowing atmosphere of pure hydrogen. The influence of charge material purity as well as other technological parameters on GaSb crystals quality was investigated. High purity undoped GaSb single crystals were grown with residual acceptors concentration $<1.4 \times 10^{17} \mathrm{~cm}^{-3}$ and high mobility $\approx 690 \mathrm{~cm}^{2} / \mathrm{Vs}$ (at $300 \mathrm{~K}) . P$-type GaSb crystals were doped with silicon (carrier concentration up to $2 \times 10^{19} \mathrm{~cm}^{-3}$ ) and with zinc (up to $1 \times 10^{19} \mathrm{~cm}^{-3}$ ). Tellurium doped $n$-type GaSb single crystals were obtained with concentration up to $2 \times 10^{18} \mathrm{~cm}^{-3}$. Electrical parameters were investigated by the Hall measurements $(300 \mathrm{~K}$ and $77 \mathrm{~K})$. Temperature dependent Hall measurements $(10 \div 300 \mathrm{~K}$ ) were used to compare the quality of undoped GaSb (obtained from $\mathrm{Sb}$ of different purity). Dopant concentration was estimated by glow discharge mass spectroscopy analysis. Axial and radial distribution of carrier concentration were investigated especially for Te-doped crystals (low segregation coefficient of $\mathrm{Te}$ in GaSb). Great contribution of compensation and self-compensation mechanisms is shown especially for the beginning part of grown crystals and for low Te-doping level. Radial distribution of physical properties for crystals grown in $\langle 100\rangle$ direction is not axisymmetrical especially for doped GaSb crystals.
\end{abstract}

PACS: 81.05.Ea, 81.10.Fq, 81.10.-h, 81.10.St, 72.80.Ey, 71.55.Eq, 61.72.uj

\section{Introduction}

Gallium antimonide is particularly interesting as substrate material for various ternary and quaternary III-V compounds due to its good lattice match to GaSb $\left(\Delta a / a \approx 1 \times 10^{-3}[1,2]\right)$. At present, current research and developments are focused on high quality materials growth and understanding materials properties. GaSb based structures are suitable for optoelectronic, photovoltaic [3-5] and microwave devices such as photodetectors [6], laser diodes [2, 7] and light sources for gas-sensing applications $[8,9]$.

Undoped Czochralski-grown GaSb has high residual acceptors concentration $\approx 1.5 \times 10^{17} \mathrm{~cm}^{-3}(300 \mathrm{~K})$ related to vacancies $\left(\mathrm{V}_{\mathrm{Ga}}\right)$, antisites $\left(\mathrm{GaSb}_{\mathrm{Sb}}\right)$ and complexes $\left(\mathrm{V}_{\mathrm{Ga}} \mathrm{Ga}_{\mathrm{Sb}}\right)$ of doubly ionized nature [10,11]. There is still big interest in growth of GaSb crystals with reduced residual acceptors. Improvement of ingots properties, substrate wafers, and "buffer" layers is of great importance for future devices fabrication [3]. In the present work, physical properties distribution and its homogeneity through the whole volume was investigated for GaSb crystals grown in $\langle 100\rangle$ direction. Radial distribution of carrier concentration was checked for characteristic crystallographic directions for (100) GaSb wafers.

\section{Undoped GaSb and growth conditions}

The main problem encountered during growth is the appearance of an oxide film on the GaSb melt surface. The scum has been identified as $\mathrm{Ga}_{2} \mathrm{O}_{3}$ [12], it impairs the seeding of the melt and promotes twinning during the subsequent growth. Figure 1 shows four series of crystals prepared in various ways: (1) separate processes of horizontal Bridgman (HB) synthesis and Czochralski (CZ) crystallization, (2), (3), (4) modified Czochralski method, integrated with in situ synthesis. In series (3) and (4) high purity hydrogen flow was used. In the case of (4) additionally purified $\mathrm{Sb}$ and optimized process parameters were applied. Following above steps, hole concentration has been lowered significantly beneath the value $1.5 \times 10^{17} \mathrm{~cm}^{-3}$ and with very narrow spread of obtained values.

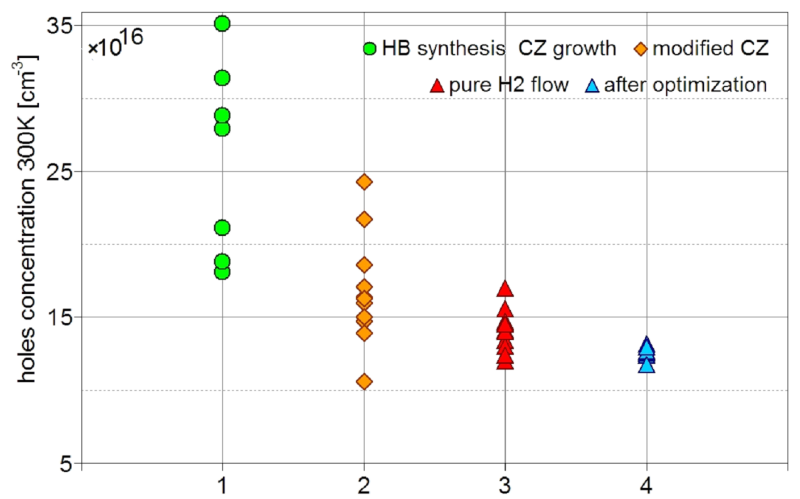

Fig. 1. Hole concentration in undoped GaSb grown in different conditions.

It is clearly seen that preparing GaSb it is absolutely necessary to reduce the number and duration time of technological procedures, to use high-purity raw materials and avoid any possibility of oxidizing. High purity hydrogen flow, as well as little amount of boric oxide $\left(\mathrm{B}_{2} \mathrm{O}_{3}\right)$ 
with as low water content as possible $(<250 \mathrm{ppm})$, allows to remove oxide scum from the melt surface and grow GaSb single crystals repeatedly. Process parameters optimization: enlarging charge weight with precise stabilization of crystal diameter $\pm 2 \mathrm{~mm}$ and lowering $\mathrm{Sb}$ excess necessary to preserve stoichiometry;enable elongation of GaSb single crystal body.

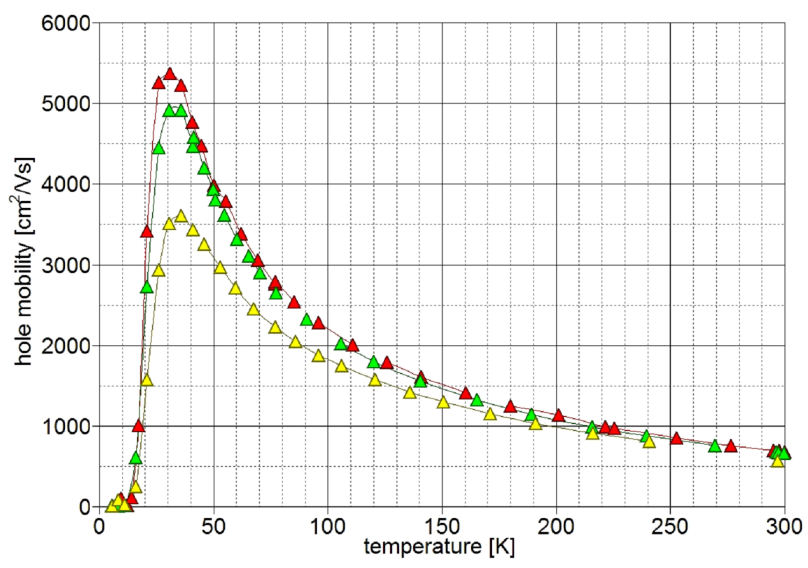

Fig. 2. Hole mobility in undoped GaSb obtained from $\mathrm{Sb}$ of high purity (red triangles) and insufficiently purified $\mathrm{Sb}$ (yellow triangles).

Hole concentration value in undoped GaSb strongly depends on growth conditions and should be kept as low as possible, but in the same time hole mobility should stay high. Undoped GaSb purity can be confirmed by low-temperature Hall measurements [13, 14]. Significant differences in low-temperature hole mobility are shown in Fig. 2. For good quality CZ-grown GaSb obtained from $\mathrm{Sb}$ of high purity (red marks) hole mobility maximum value $\left(>5300 \mathrm{~cm}^{2} / \mathrm{V} \mathrm{s}\right)$ is reached for low temperature $\approx$ $30 \mathrm{~K}$, but while insufficiently purified Sb was used (yellow marks) hole mobility maximum lowers to $3500 \mathrm{~cm}^{2} / \mathrm{V} \mathrm{s}$. Such low mobility value was reported [15] for nominally undoped commercial GaSb wafers.

\section{Axial distribution of physical properties}

Undoped GaSb has very uniform distribution of electrical properties. Hole concentration throughout the whole crystal body is in the range $(1.2 \div 1.3) \times 10^{17} \mathrm{~cm}^{-3}$. The discrepancy between values is usually less than measurement accuracy $( \pm 5 \%)$.

Silicon and zinc were used as dopants for $p$-type GaSb. All of the crystals have $p$-type conductivity. Carrier concentration in GaSb:Si measured at the beginning and end part of the single crystals is almost the same (segregation coefficient of $\mathrm{Si}$ in GaSb is very close to unity). For the lowest amount of Si $(27 \mathrm{mg} / \mathrm{kg})$ carrier concentration is $(4.3 \div 4.9) \times 10^{18} \mathrm{~cm}^{-3}$, for the biggest Si dose $(240 \mathrm{mg} / \mathrm{kg})$ carrier concentration is $(1.8 \div 3.1) \times 10^{19} \mathrm{~cm}^{-3}$. Electrically active part of $\mathrm{Si}$ has been estimated $(1 \div 0.85)$ and is practically independent of $\mathrm{Si}$ concentration.
By now very little is known about $\mathrm{Zn}$-doped CZ-grown GaSb. In this article it is shown for the first time that segregation coefficient of zinc in $\mathrm{GaSb}$ varies with doping level (Fig. 3). For the lowest amount of zinc $(50 \mathrm{mg} / \mathrm{kg}$ ) carrier concentration lowers along crystal axis from $2.7 \times 10^{18} \mathrm{~cm}^{-3}$ to $2.0 \times 10^{18} \mathrm{~cm}^{-3}$, but for the biggest $\mathrm{Zn}$ dose $(211 \mathrm{mg} / \mathrm{kg})$ hole concentration rises along crystal axis from $7.4 \times 10^{18} \mathrm{~cm}^{-3}$ to $1.4 \times 10^{19} \mathrm{~cm}^{-3}$. Number of acceptors activated by $p$-type doping (for each Zn atom) also strongly depends on zinc concentration and rises from $\approx 1.5$ (for $\approx 1 \times 10^{18} \mathrm{~cm}^{-3}$ ) up to $\approx 2$ (for $\left.\approx 5 \times 10^{18} \mathrm{~cm}^{-3}\right)$.

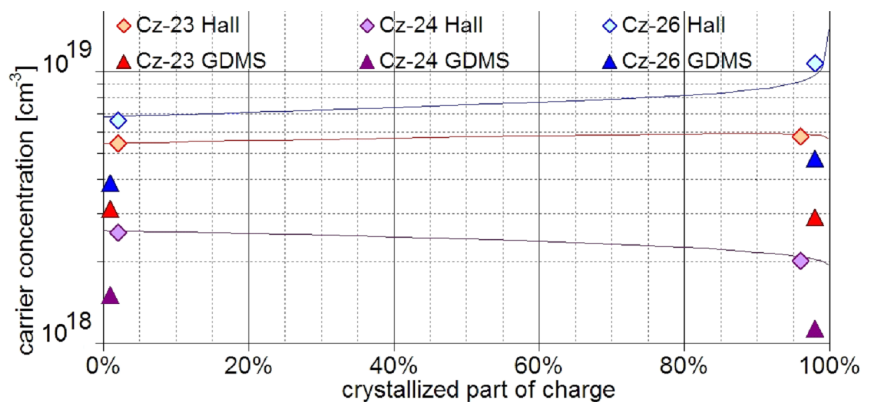

Fig. 3. Hole concentration (Hall) measured at $300 \mathrm{~K}$ and $\mathrm{Zn}$ concentration (GDMS) along GaSb:Zn crystals axis ( $\mathrm{Zn}$ doses: $50 \div 211 \mathrm{mg} / \mathrm{kg}$ ).

Low Te-doped GaSb usually has very inhomogeneous distribution of physical properties [16] caused by compensation mechanisms. In this work, for lowest amount of tellurium $(30 \mathrm{mg} / \mathrm{kg})$ first part $(\approx 40 \%)$ of the single crystal shows $p$-type conductivity. Compensation and self-compensation mechanisms lead to $n$-type conductivity in the rest of single crystal. Using bigger amount of Te $(51 \mathrm{mg} / \mathrm{kg}$ up to $136 \mathrm{mg} / \mathrm{kg}$ ) the whole body of GaSb:Te single crystal has $n$-type (Fig. 4). Carrier concentration measured at the end of single crystals was almost identi$\mathrm{cal} \approx 1.5 \times 10^{18} \mathrm{~cm}^{-3}$

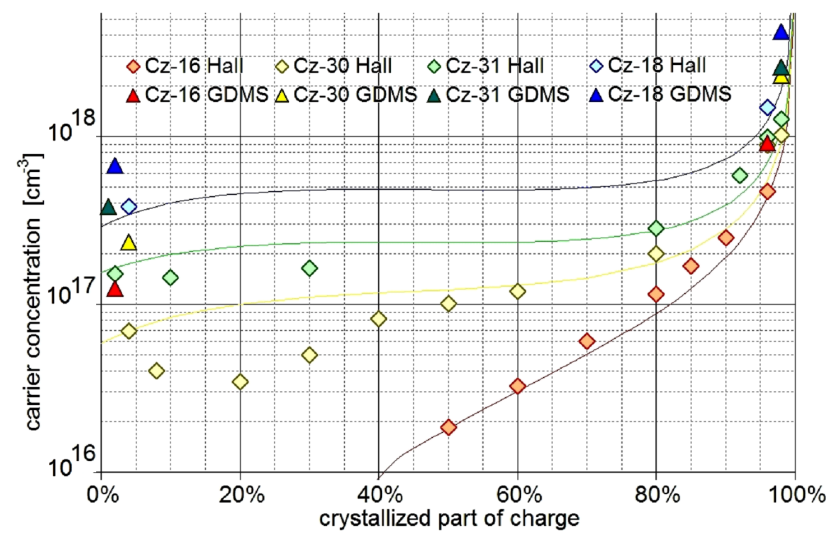

Fig. 4. Electron concentration (Hall) measured at $300 \mathrm{~K}$ and $\mathrm{Te}$ concentration (GDMS) along GaSb:Te crystal axis (Te doses: $30 \div 136 \mathrm{mg} / \mathrm{kg}$ ). 
Axial distribution of carrier concentration in GaSb:Te crystals shows that it is $\approx 10$ times bigger at the end than at the beginning of a single crystal. For crystals with $\mathrm{Te}$ concentration at the beginning lower than $3 \times 10^{17} \mathrm{~cm}^{-3}$, slight lowering of electron concentration is observed due to self-compensation mechanisms ( $\mathrm{Te}_{\mathrm{Sb}}$ donor in $\mathrm{GaSb}$ forms with native point defect $\mathrm{V}_{\mathrm{Ga}} \mathrm{Gasb}$ triple acceptor complex $\left.\mathrm{V}_{\mathrm{Ga}} \mathrm{Ga}_{\mathrm{Sb}} \mathrm{Te}_{\mathrm{Sb}}[13,16]\right)$. Electrically active part of Te lowers with dopant concentration: from the value of 0.99 (for low Te concentration $1.2 \times 10^{17} \mathrm{~cm}^{-3}$ ) down to $\approx 0.42$ (for $\approx 5 \times 10^{18} \mathrm{~cm}^{-3}$ at crystal tail).

\section{Radial distribution of carrier concentration}

Radial distribution of electrical properties was investigated for (100) wafers prepared according to SEMI Standard. Undoped GaSb has almost homogeneous distribution of electrical parameters throughout the whole crystal body. Similar homogeneity is observed for $p$-type $\mathrm{GaSb}$ doped by silicon or zinc (for $k \approx 1$ ). For GaSb:Zn (100) wafers, a little bit higher acceptor concentration is observed (Fig. 5) near the primary flat (PF) edge of wafer, the lowest is near the secondary flat (SF). Zinc incorporates $\left(\right.$ as $\mathrm{Zn}_{\mathrm{Ga}}$ ) easier at (111) Ga facet plane at convex crystal-melt interface.

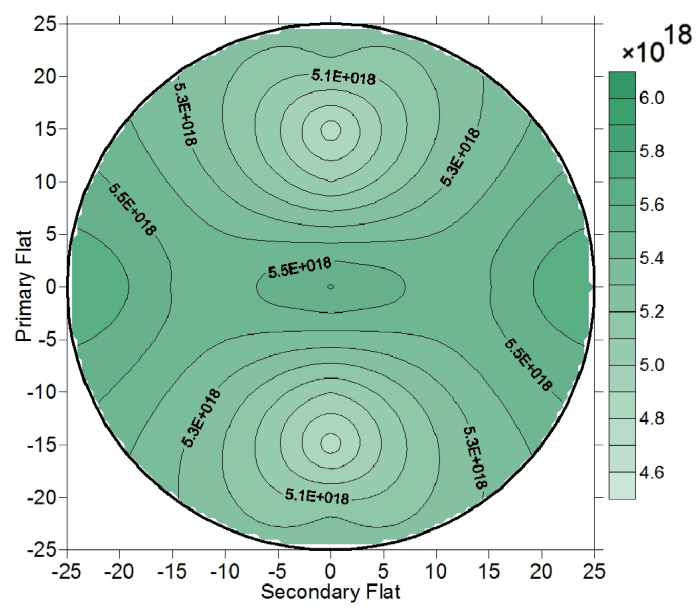

Fig. 5. Radial distribution of hole concentration in Zn-doped GaSb.

Doping by tellurium causes the opposite situation. Te atoms occupy $\mathrm{Sb}$ sublattice $\left(\mathrm{Te}_{\mathrm{Sb}}\right.$ ), so (111)Sb facet plane at interface is preferred. In $p$-type as well as in $n$-type wafers donor concentration $\left(\mathrm{Te}_{\mathrm{Sb}}\right.$ ) is bigger near $\mathrm{SF}$ edge than near PF edge (Fig. 6). Because of low value of segregation coefficient for $\mathrm{Te}(\approx 0.35)$ carrier concentration inhomogeneity can easily be seen. For bigger amount of Te-dopant the lowest electron concentration is observed in the central part of wafer (mainly because of convex crystal-melt interface shape). Radial distribution of physical properties is not axisymmetrical for (100) GaSb wafers.

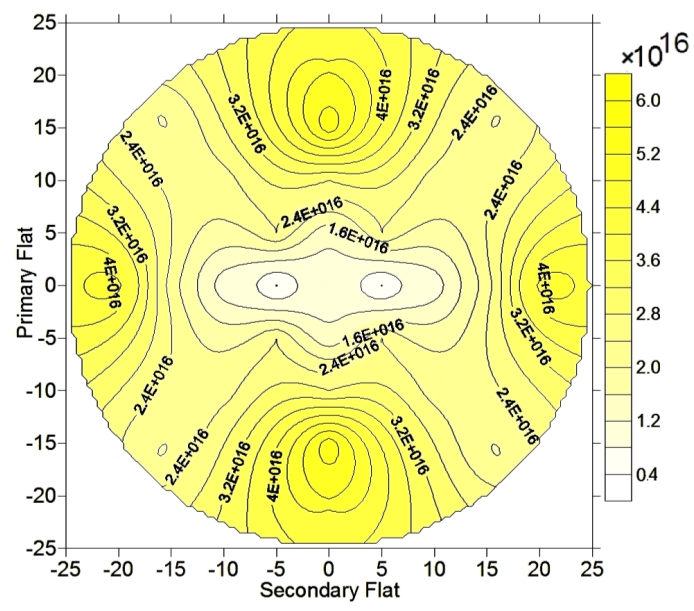

Fig. 6. Radial distribution of electron concentration in $n$-type part of low Te-doped GaSb.

\section{Conclusions}

Applying integrated process of in situ synthesis and modified Czochralski crystal growing allows for minimizing of whole process duration time and also reducing the quantity of technological procedures accompanying each stage of mechanical and chemical preparation of charge. Best quality of undoped GaSb can be achieved only by using sufficiently purified $\mathrm{Sb}$ and pure hydrogen flow.

Undoped GaSb has very uniform distribution of electrical properties throughout the whole crystal body. Good homogeneity of electrical properties can also be achieved for $p$-type GaSb doped with $\mathrm{Si}$ or $\mathrm{Zn}$ (but only for $\mathrm{Zn}$ concentration $\approx 3 \times 10^{17} \mathrm{~cm}^{-3}$ ) when segregation coefficient is close to unity. Segregation coefficient of $\mathrm{Zn}$ in GaSb lowers for bigger amount of Zn dopant.

For Te-doped crystals low value of segregation coefficient is responsible for bigger inhomogeneity of electrical properties (axial and radial segregation of Te). For (100) wafers donor defects distribution is not axisymmetrical - tellurium defects $\left(\mathrm{Te}_{\mathrm{Sb}}\right)$ prefer (111) Sb facets at crystal-melt interface. For low Te-doped GaSb (with Te concentration at the beginning less than $3 \times 10^{17} \mathrm{~cm}^{-3}$ ) in the first part of crystal body self-compensation mechanisms are clearly visible. Electron concentration lowering along crystal axis is due to additional formation of acceptor defects $\left(\mathrm{V}_{\mathrm{Ga}} \mathrm{GaSb}_{\mathrm{Sb}} \mathrm{V}_{\mathrm{Ga}}\right.$ and $\left.\mathrm{V}_{\mathrm{Ga}} \mathrm{GaSb}_{\mathrm{Sb}}\right)$.

\section{References}

[1] W.T. Tsang, T.H. Chiu, W. Kisker, J.A. Ditzenberger, Appl. Phys. Lett. 46, 283 (1985).

[2] H. Lee, P.K. York, R.J. Menna, R.U. Martinelli, D. Garbuzov, S.Y. Narayan, J. Cryst. Growth 150, 1354 (1995).

[3] S. Luca, J.L. Santailler, J. Rothman, J.P. Belle, C. Calvat, G. Basset, A. Passero, V.P. Khvostikov, N.S. Potapovich, R.V. Levin, J. Sol. Ener. Eng. 129, 304 (2007). 
[4] V.P. Khvostikov, J.L. Santailler, J. Rothman, J.P. Bell, M. Couchaud, C. Calvat, G. Basset, A. Passero, O.A. Khvostikova, M.Z. Shvarts, AIP Conf. Proc. 890, 198 (2007).

[5] M.A. Afrailov, L.A. Andreev, E.V. Kunitsyna, M.P. Mikhailova, Y.P. Yakovlev, K. Erturk, AIP Conf. Proc. 899, 447 (2007).

[6] D. Lackner, O.J. Pitts, S. Najmi, P. Sandhu, K.L. Kavanagh, A. Yang, M. Steger, M.L.W. Thewalt, Y. Wang, D.W. McComb, C.R. Bolognesi, S.P. Watkins, J. Cryst. Growth 311, 3563 (2009).

[7] J.G. Kim, L. Shterengas, G.L. Belenky, Appl. Phys. Lett. 83, 1926 (2003).

[8] A. Ducanchez, L. Cerutti, P. Grech, F. Genty, E. Tournie, Electron. Lett. 45, 265 (2009).

[9] M. Motyka, G. Sęk, K. Ryczko, J. Misiewicz, T. Lehnhardt, S. Höfling, A. Forchel, Appl. Phys. Lett. 94, 251901 (2009).
[10] F. Meinardi, A. Parisini, L. Tarricone, Semicond. Sci. Technol. 8, 1985 (1993).

[11] C.C. Ling, M.K. Lui, S.K. Ma, X.D. Chen, S. Fung, C.D. Beling, Appl. Phys. Lett. 85, 384 (2004).

[12] N. Kitamura, T. Kikuchi, M. Kakehi, T. Wada, Jpn. J. Appl. Phys. 23, 1534 (1984).

[13] P.S. Dutta, V. Prasad, H.L. Bhat, J. Appl. Phys. 80, 2847 (1996)

[14] M.K. Lui, C.C. Ling, Semicond. Sci. Technol. 20, 1157 (2005)

[15] F. Meinardi, A. Parsini, L. Tarricone, Semicond. Sci. Technol. 8, 1985 (1993).

[16] A.G. Milvidskaya, A.Y. Polyakov, G.P. Kolchina, A.G. Milnes, A.V. Govorkov, N.B. Smirnov, I.V. Tunitskaya, Mater. Sci. Eng. B 22, 279 (1994). 